\title{
Contribuições da Teoria Histórico-Cultural na formação de professores de crianças pequeñas
}

\section{Contributions from the Historical-Cultural Theory for the teacher education of young children}

\begin{abstract}
Dra. Elieuza Aparecida de Lima*, Dra. Cristiane Regina Xavier Fonseca-Janes**, Dra. Amanda Valiengo*** *Departamento de Didática da Universidade Estadual Paulista (Unesp), FFC, Campus de Marília SP, BR, ** Universidade Estadual Paulista (Unesp), FFC, Campus de Marília, SP, BR, Prefeitura Municipal de Bauru, Faculdades Integradas Coração de Jesus (FAINC), *** Departamento de Ciências da Educação da Universidade Federal de São João Del Rei, MG, BR.
\end{abstract}

\section{Resumo}

Esta pesquisa objetivou refletir sobre o papel do educador no desenvolvimento cultural da criança entre zero e três anos, especialmente no desenvolvimento da linguagem oral. Os fundamentos teóricos advêm da Teoria ou Psicologia Histórico-Cultural. Os estudos nesta perspectiva revelam-se como essenciais por suas implicações pedagógicas voltadas para a organização de situações e atividades educativas humanizadoras nos primeiros anos da infância. O papel potencialmente mediador do educador implica no estabelecimento de uma relação direta de comunicação com a criança, demonstrando ações com objetos e atitudes, orientando, questionando, propondo, estabelecendo contato com ela, em situações pedagógicas orientadas ao desenvolvimento integral da linguagem.

Palavras chave: 1. Psicologia Histórico-Cultural, 2. Desenvolvimento da Linguagem, 3. Infância.

\begin{abstract}
This research aimed to think about the educator role in the cultural development of the zero to three-year-old child, mainly the oral language development. THe theoretical basis come from the Historical-Cultural Psychology or Theory. From this perspective, the studies are essential for their pedagogical implications led to the organization of the situations and humanized educational activities during the early years of the childhood. The role potentially mediator of the educator implies the establishment of a direct relation of communication with the child by showing actions with objects and attitudes, guiding, questioning, setting up contact with the child in pedagogical situations oriented for the whole language development.

Key words: Historical-Cultural Psychology. Language development. Childhood.
\end{abstract}

\section{Introdução}

Embora a literatura escolhida para estas reflexões não seja datada como recente, suas contribuições podem ser consideradas atuais para pensarmos a educação e a atuação do professor. Vale ressaltar que tardiamente os escritos de L. S. Vygotski (1896-1934), colaboradores e seguidores começaram a ser estudados e divulgados no Brasil, por volta dos anos de 1980, embora suas pesquisas e trabalhos tenham sido iniciados há quase um século.
Já naquele momento histórico, os trabalhos de Vygotski (1995) demonstraram que o psiquismo (inteligência e personalidade) é formado por meio da vida concreta do homem, condicionado pelas relações sociais. Nesse sentido, pela primeira vez, essa teoria apresenta o princípio da unidade do psiquismo e da atividade humana como constituintes da base fundamental dos estudos representativos da Teoria Histórico-Cultural.

Para Vygotski (1995), no processo de desenvolvimento infantil, o adulto e outros parceiros mais experientes tornam-se mediadores e criadores de mediações na relação da criança com o conhecimento a ser apropriado. A presença e mediação da geração adulta possibilitam que os processos psicológicos se desenvolvam: nos primeiros dias de vida, as crianças dão ao mundo respostas instintivas; com os adultos e parceiros mais experientes - criando mediações entre o mundo objetivo e a criança pequena - inicia-se o processo de apropriação e desenvolvimento dos processos psicológicos mais complexos, também denominados de processos interpsíquicos. Inicialmente, vivenciados coletivamente, posteriormente, esses processos são internalizados, sendo realizados no nível psíquico interno da criança. Isso melhor acontece a partir de um ensino intencional e direcionado a provocar um desenvolvimento pleno desde que as crianças são bem pequenininhas.

No que se refere à Educação Infantil e seu papel nesse desenvolvimento cultural pleno, numa retrospectiva histórica, no Brasil, os anos de 1980 e 1990 marcam decisivamente as discussões conceituais sobre esse nível da educação, com avanços referentes à questão do desenvolvimento da criança quase sem dependência das condições externas, sendo determinado biologicamente e transcorrendo de maneira praticamente estereotipada.

A partir de políticas públicas dirigidas à garantia, pelo menos do ponto de vista legal, de direitos infantis fundamentais, tais como o direito a uma educação de qualidade para todas as crianças, a Constituição Brasileira (BRASIL, 1988), a Lei n. 9394 (BRASIL, 1996) e o Parecer n. 20 (BRASIL, 2009) registraram 
legalmente a movimentação social e política em expansão e aprofundamento.

Os estudos de Vygotski (1995; 1998a; 1998b; 2004) vêm ao encontro desse momento histórico brasileiro, com a compreensão de que as condições de vida, educação e atividade são fontes de desenvolvimento. Esse autor concebeu o desenvolvimento da linguagem oral caracterizado pela história da formação de uma das funções mais importantes do comportamento cultural da criança, surgida de sua experiência cultural. Sua apropriação dá novo rumo à formação, ao desenvolvimento e ao aperfeiçoamento de outras funções psíquicas superiores. Nessa perspectiva, a aprendizagem da linguagem oral tem um valor único para formação e aperfeiçoamento de qualidades humanas nas pessoas (VYGOTSKI, 1995).

Ao considerarmos o papel interventor e mediador ocupado pelo professor nas relações educativas, os pressupostos teóricos histórico-culturais contribuem para refletirmos sobre a constituição de realizações humanizadoras na escola de Educação Infantil, em especial aquelas referentes às motivações direcionadas a aprendizagem da linguagem. Para entendermos a importância da linguagem na ação prática do professor, achamos por bem discutir a concepção de linguagem em Vygotski.

\section{A concepção de linguagem em Vygotski}

O desenvolvimento da linguagem para Vigotski é percebido como um processo em mudança e transformação, assumindo um papel vital no desenvolvimento intelectual, tanto no aspecto da ontogênese quanto da filogênese.

$\mathrm{Na}$ filogênese da escrita, nossos antepassados comunicavam-se inicialmente por meio de grunhidos. Com o desenvolvimento da espécie, começaram a criar formas mais complexas de comunicação, primeiro símbolos ideográficos e posteriormente a escrita rudimentar para evoluir à escrita de hoje; dizer que não existia linguagem nos primórdios do desenvolvimento da espécie é incorreto, mas sim que ela permeava o meio e foi se desenvolvendo.

Numa investigação preliminar das obras de Vygotski, tanto acerca da filogênese quanto da ontogênese da linguagem e do pensamento, leva-se a impressão de que esses fenômenos são duas retas paralelas e distintas e, em um determinado momento, advindo com a interação do meio, essas retas convergem e dão início às ações mais complexas no intelecto humano. Entretanto, num olhar minucioso, percebe-se que "seria errado considerar o pensamento e a fala1 [linguagem] como dois processos independentes, paralelos, que se cruzam em determinados momentos e influenciam mecanicamente um ao outro" (VYGOTSKI, 1998a, p.150). O significado da palavra só passa a ser um fenômeno do pensamento quando é internalizado por mediadores externos, e realmente só passa a ter sentido dentro das práticas sociais.

\footnotetext{
${ }^{1}$ Percebeu-se durante o estudo dos textos que fundamentam este artigo que, muitas vezes, a tradução da palavra fala é remetida à palavra linguagem. Sendo este trecho um deles.
}

Segundo Vygotski, para que os indivíduos possam operar com os signos, faz-se necessário um elo intermediário entre estímulo e resposta $(\mathrm{S} \rightarrow \mathrm{R})$ : esse elo seria a mediação. Essa operacionalização se dá por um ato complexo, caracterizando-se como um processo dialético do meio e do indivíduo onde estão envolvidos estímulo, mediação e resposta (VYGOTSKI, 1995).

Vygotski (1995, 1998a; 1998b; 2004) evidencia haver uma diferenciação entre a memória da criança e a de um adulto, e isto se deve ao próprio desenvolvimento, ou seja, a criança utiliza-se de símbolos externos para lembrar-se de algo, enquanto o adulto já tendo interiorizado esses signos externos (internalização) terá condições de operacionalização do pensamento hipotético-dedutivo (FONSECA-JANES; LIMA, 2013).

Ao se apropriar da fala, a criança usa palavras para criar planos de ação, o que possibilita um leque maior a ela na solução de problemas. Suas operações práticas serão, a partir daí, cada vez menos impulsivas e espontâneas. Assim, nessas operações, a criança divide o problema a ser solucionado em duas partes consecutivas: 1) planeja por meio da fala e 2) executa por meio de uma atividade visível. Esta manipulação direta sobre o objeto é posteriormente interiorizada e substituída por um processo psicológico mais complexo.

Para Vygotski (1998a; 1998b), a fala possibilita a efetiva manipulação de objetos, controla o comportamento da criança, a leva a se tornar sujeito e objeto de seu próprio comportamento. Assim, a fala é um instrumento valioso para o desenvolvimento humano, pois tem a responsabilidade de ampliar o campo conceptual da criança, levando-a a refletir o mundo exterior.

Vygotski (1998a) argumenta que, dentre os vários problemas ligados à complexidade do pensamento e da linguagem, um deles está diretamente nas interpretações errôneas da fala interior. Para o autor, a fala interior não é de forma alguma apenas fala motora, mas antes uma atividade intelectual e afetivo-volitiva, uma vez que inclui os motivos da fala e o pensamento expresso em palavras. A fala exterior é uma fala social, ou seja, é a tradução, materialização, objetivação do pensamento em palavras. A fala interior é condensada e abreviada, porque revela a interiorização do pensamento.

A fala interior é, em grande parte, um pensamento que expressa significados puros. Ela é dinâmica, instável e inconstante, flutuando entre a palavra e o pensamento. $\mathrm{O}$ plano mais interiorizado do que a fala interior é o próprio pensamento. Todos os pensamentos criam uma conexão, preenchem uma função e resolvem problemas. $\mathrm{O}$ pensamento tem sua própria estrutura, não consistindo em unidades separadas. O pensamento é um todo, mas é expresso em palavras separadas, obedecendo a um desenvolvimento sequencial. E a transição do pensamento à palavra passa pelo significado (VYGOTSKI, 1998a, p. 190).

Pelo exposto até aqui, é possível depreender que a concepção de linguagem de Vygotski e os estudos de pesquisadores advindos da Teoria Histórico-Cultural podem contribuir para formação de professores de crianças pequenas, conforme discutimos no tópico a seguir. 


\section{Teoria histórico-cultural e linguagem oral}

Já nos primeiros meses de vida, a linguagem oral constitui suas bases e se expressa numa comunicação sem palavras, fundamentada nas emoções compartilhadas pela criança e pelas pessoas do seu entorno. Lísina (1987) constatou que, nos primeiros dias depois do nascimento, a criança não demonstra necessidade de comunicação, ainda que requeira a ajuda e atenção do adulto. Somente ao final do primeiro mês, o bebê começa a estruturar alguns componentes da necessidade de comunicação, quando se pode observar uma atividade dirigida ao adulto com traços de uma atividade comunicativa.

Essa primeira atividade humana é denominada de comunicação situacional emocional. A comunicação emocional da criança com o adulto expressa a manifestação de sentimentos - não de ideias relacionados à satisfação e à insatisfação das relações mais gerais existentes entre eles. Sob a base da comunicação emocional, a comunicação oral se forma, inicialmente, elementar e incompleta, expressa por mímicas, gestos, movimentos e ações.

Essa compreensão encaminha-nos para a explicitação da historicidade da constituição da linguagem oral nas pessoas. Não se trata de capacidade inata ao homem, mas constituída no interior das relações, atividades e condições concretas de vida e educação de cada pessoa. Para nós, professores, pais e mães essa historicidade da aprendizagem da fala tem algum valor especial? Por não ser herdada biologicamente, essa necessidade é provocada pela influência de determinadas condições, dentre as quais a necessidade objetiva e concreta que o bebê tem de atenção e solicitude por parte dos circundantes, já que não possui condições de satisfazer suas necessidades de alimentação e de higiene, todas essenciais para sua sobrevivência. Nesse momento, o interesse pelo adulto não se constitui numa necessidade de comunicação, mas de satisfação de necessidades básicas de sobrevivência, conforme já apontado. No entanto, a conduta das pessoas - os modos como a mãe e o professor se dirigem ao bebê, embora ele não seja capaz de realização de uma atividade comunicativa por meio da fala - contribui para que o bebê vá tomando parte nessa atividade de comunicação com o outro.

O educador é, então, essencial como parceiro que antecipa a iniciativa da necessidade de comunicação na criança. $\mathrm{O}$ adulto atrai a criança para uma atividade e ambos agem ativamente nesse processo, graças à capacidade do bebê para receber diferentes estímulos e responder a eles, durante as relações com outras pessoas.

Com o compromisso educativo de ampliação dos relacionamentos e possibilidades de atuação e atividade da criança pequena, o educador pode, além de se tornar referência como pessoa falante, provocadora do desejo de comunicação na infância, atuar intencionalmente.

Nesse processo, a pronúncia, a imitação e a combinação de sons são elementos importantes para o desenvolvimento da comunicação oral, com contribuição para a aprendizagem da capacidade de diferenciação de sons (constituindo o ouvido fônico) e de pronunciação. Esse ato comunicativo possibilita que a linguagem do adulto influencie a criança, ao mesmo tempo em que a própria criança assume um papel ativo na comunicação. Nos primeiros meses e anos de vida, os aprendizados da linguagem ocorrem nos momentos de cuidado da criança: alimentação, higiene e sono

Do nascimento até dois meses e meio/três meses, torna-se essencial a provocação da concentração visual e auditiva do bebê. $\mathrm{O}$ adulto cria condições para que o bebê se concentre em seu rosto ou detenha o olhar nos brinquedos de cores vivas; em outras situações, orienta o bebê para seguir objetos em movimento, escutar diferentes sons e a linguagem das pessoas do seu entorno, sua voz, o som do chocalho e outros brinquedos sonoros (POPOVA, 1985, p. 23).

O contato com o adulto e suas conversas com o bebê exigem conteúdo simples, mas não infantilizado. São contatos caracterizados principalmente pela expressão de sentimentos do adulto e sua tentativa de acalmar e agradar o bebê. Tanto no primeiro mês, quanto no mês seguinte, o sono é alternado por momentos em que o adulto exerce grande influência sobre a visão, a audição e o tato do bebê.

No segundo mês de vida, as reações do bebê são mais expressivas, com risos e gritos. Nas conversas com o adulto, a criança demonstra uma comunicação cada vez mais ativa. Aos três meses, surge o complexo de animação, caracterizado pelo desenvolvimento da reação emocional expressiva da criança, como resultado das influências educativas do adulto. Contemplam-se as reações mímicas, motoras e articulatórias.

Nesse momento, o adulto pode criar outras formas de mediação da criança com o mundo, ao introduzir objetos e brinquedos no seu processo de comunicação com o bebê. A movimentação de objetos e brinquedos pendurados, bem como agitar brinquedos sonoros tornam-se ações dirigidas ao desenvolvimento da visão e da audição do bebê e também de sua necessidade de comunicação. $\mathrm{Na}$ sua comunicação com a criança, o adulto se dirige a ela como sujeito ativo na conversação. Chama a criança pelo nome, diz "Bom dia"; faz perguntas e as responde. Essas intervenções educativas são necessárias para que a criança escute a linguagem oral.

Até o final do primeiro semestre de vida as reações vocais adquirem certa independência. Nessa etapa, uma das tarefas essenciais dos educadores é a criação de situações em que as manifestações vocais, as pronúncias e os balbucios se ampliem e contribuam para o desenvolvimento geral do aparato articulatório e da concentração auditiva.

A pronúncia de sons é observada também na atividade independente da criança. A ampliação da quantidade e da composição das reações vocais depende, assim, de situações pedagógicas intencionalmente organizadas para o bebê, entendendo-se a importância da comunicação durante o cuidado do bebê (alimentação, higienização e sono), com a possibilidade de motivação e garantia de estado emocional positivo da criança pequena (POPOVA, 1985).

Para tanto, um trabalho educativo planejado e organizado nas instituições infantis se faz necessário, de acordo com Popova (1985, p. 21-22), “[...] a 
expressividade da entonação da linguagem da educadora tem especial importância. [...] O conteúdo das 'conversações' do adulto torna-se mais complexo à medida que a criança se desenvolve [...]".

No período compreendido dos cinco/seis aos nove meses de idade, o aperfeiçoamento contínuo da percepção visual e auditiva, dos movimentos e o surgimento da orientação no meio circundante influenciam decisivamente no desenvolvimento da linguagem. Essa ideia é provocadora de atitudes educativas pautadas na atenção individualizada do adulto nos seus relacionamentos mais diretos com os bebês, especialmente nos momentos da rotina diária nas instituições de educação infantil, mediando situações necessárias para a formação da linguagem oral, dos movimentos, hábitos, dentre outras qualidades essenciais à humanização nos primeiros anos de vida.

Dos nove/dez meses a doze meses, a intenção pedagógica dirige-se para a ampliação das possibilidades de conhecimento acerca dos nomes de objetos e brinquedos circundantes, dos movimentos e ações com a intenção de desenvolvimento do balbucio, da imitação e ativação de palavras aprendidas como: mamãe, papai etc.

Ao final do primeiro ano de vida, começam a se formar as reações às palavras com seus aspectos fônico e semântico relacionados, isto é, a criança assimila as primeiras palavras e, sobre esta base, inicia-se a comunicação oral. Entretanto, as primeiras palavras apreendidas não são utilizadas pela criança na atividade comunicativa, mas principalmente na observação de objetos circundantes e na realização de ações com esses objetos e brinquedos, ou na recordação de objetos conhecidos. No processo de ação e na observação de objetos e brinquedos, a criança pronuncia, em lugar de palavras, sons isolados e combinação de sons (formando, às vezes, palavras balbuciadas).

Em geral, será após os dezoito meses de idade que se estabelecerá a comunicação oral articulada tal como a dos adultos. Com a apropriação e aperfeiçoamento dessa forma de comunicação, a criança já não só responde à motivação do adulto, como também utiliza as palavras com iniciativa própria, nas atividades com objetos. $\mathrm{O}$ surgimento da linguagem espontânea é o marco do trabalho educativo realizado nos diferentes ambientes onde a criança vive. Esse marco evidencia o caráter e o conteúdo da comunicação do adulto, expressa o vocabulário acumulado pela criança e outros aspectos linguísticos, bem como a utilização do vocabulário apreendido na comunicação da criança com outras pessoas (LÍSINA, 1987).

Ao final dos dois primeiros anos, a criança começa a usar as palavras aprendidas na comunicação com o outro, nas ações com objetos. O desenvolvimento da ação com objetos antecede a apropriação de palavras (o acúmulo de vocabulário passivo): a atividade infantil com objetos oferece possibilidades de desenvolvimento da linguagem e de outras qualidades psíquicas (memória, atenção, percepção, pensamento, etc.).

Os passeios nos diferentes ambientes sociais e as atividades educativas organizadas sistematizadas possibilitam, pois, a familiarização com animais e seus nomes, com diferentes tipos de transportes e objetos, processo fundamental para o desenvolvimento da linguagem. Os conhecimentos e as percepções adquiridos nesses momentos podem ser resgatados em outras ocasiões, por meio de conversas com as crianças sobre as atividades e os passeios realizados. Os conteúdos da memória e da percepção da criança podem ser demonstrados e ativados nessas atividades de expressão e de comunicação.

Nas instituições de Educação Infantil, com a perspectiva de uma atividade docente potencializadora na formação humana das crianças, o adulto se entende e age como quem as ajuda a se inserirem na cultura, assumindo o papel mediador da aprendizagem, ajudando-as a refletir sobre o seu próprio processo de aprendizagem e de desenvolvimento cultural.

A partir da ação com os objetos, emerge o jogo de faz de conta que também auxilia no desenvolvimento da linguagem. Durante o jogo independente, as crianças realizam diferentes ações com brinquedos, dentre as quais ações denominadas específicas, investigativas e não específicas. As específicas são aquelas correspondentes à utilização ou finalidade dos objetos (com a colher se come e se dá comida à boneca). Já ações investigativas se relacionam à análise do objeto e as peças que o constituem, especialmente com o uso das mãos. As ações não-específicas se caracterizam pela simples manipulação. Para Popova (1985), ações específicas aparecem acompanhadas três vezes mais de manifestações vocais do que as ações investigativas ou as não específicas.

Além do jogo, os momentos de leitura e contação de histórias são motivadores do processo de aperfeiçoamento da oralidade infantil. Nos livros de literatura infantil, particularmente, ilustrações e gravuras constituem meio efetivo para o desenvolvimento da linguagem infantil: na atividade de leitura ou/e de contação de histórias, o adulto busca a atenção da criança pequena, mostra as diversas imagens da ilustração remetendo-lhes seus nomes. Consequentemente, pouco a pouco, a criança vai aprendendo não só os nomes das pessoas, objetos ou animais que aparecem nas ilustrações, mas também as ações nelas incluídas.

O papel do educador exige, assim, o estabelecimento de relações diretas de comunicação com a criança. $\mathrm{Na}$ sua relação com ela, a tarefa educativa se dirige à demonstração, orientação, questionamento, proposições, conversas; ao oferecimento de situações pedagógicas orientadas ao desenvolvimento integral da linguagem. Além do que, com a compreensão do seu papel ativo no desenvolvimento da linguagem oral pela criança, o educador envolve a família nesse processo educativo. Com os familiares da criança, busca-se conhecimento sobre as palavras utilizadas pela criança em suas ações e conversas no âmbito domiciliar.

Em nossa reflexão até aqui, a compreensão do desenvolvimento gradual da linguagem ao longo dos três primeiros anos de vida se expressa em etapas evolutivas, ao considerarmos que o conteúdo da comunicação emocional da criança com o adulto é possibilitado pelas particularidades existentes em cada mês de vida.

O processo de comunicação da criança e do adulto é, em síntese, a fonte fundamental de formação e 
aperfeiçoamento da linguagem oral infantil. A linguagem do educador torna-se modelo e exemplo para a apropriação da linguagem materna pela criança. Isso significa que a pronúncia correta, clara e precisa de todos os sons, a manutenção do ritmo e da intensidade adequados, o modo gramaticalmente coerente e acessível à compreensão da criança em relação à fala do adulto são fatores essenciais na educação da linguagem materna na infância.

A maneira como o adulto fala com a criança, a atenção que dispensa a ela em relação a sua comunicação oral, fundamenta os êxitos infantis acerca do desenvolvimento da linguagem oral. Nesse sentido, o trabalho do educador se fundamenta nas possibilidades potenciais da criança que a fazem avançar, observando sempre a conduta infantil e possibilitando novas situações para sua atividade. Paulatinamente essas ações tornam-se ato voluntário (LÍSINA, 1987), e a criança passa a agir independentemente.

O desenvolvimento integral da pessoa advém, portanto, das aprendizagens realizadas dentro e fora das instituições educativas, entendendo-se o valor e a tarefa das pessoas do seu entorno na concretização e somatória de esforços para esse desenvolvimento. Com essa tarefa, a instituição de Educação Infantil cumpre seu papel ao projetar a criança para além da sua natureza biológica, provocando avanços em seus processos de humanização.

\section{Considerações finais}

Nesta exposição, o ponto de partida são mudanças no panorama investigativo relativo à pequena infância, reveladoras de novas perspectivas para os lugares assumidos pela criança na sociedade e também os novos sentidos de desenvolvimento, educação e infância decorrentes da visão da criança como sujeito de direitos.

No conjunto dessas novas perspectivas e sentidos atribuídos à criança, sua infância e educação, os estudos da Teoria Histórico-Cultural, organizados por Vygotski (1995; 1998a; 1998b; 2004), colaboradores e seguidores, revelam-se como essenciais por suas implicações pedagógicas voltadas para a organização de situações e atividades educativas humanizadoras nos primeiros anos da infância. Em especial em relação à aprendizagem da fala, esses estudos têm um impacto particular e implicações para a prática educativa domiciliar e escolar ao apontarem a iniciativa antecipadora do educador como intervenção indispensável para o surgimento da necessidade de comunicação na criança.

Ao longo da discussão, os autores mencionados revelam o adulto como quem atrai a criança a uma atividade e ambos participam ativamente neste processo e cria uma nova necessidade na criança, a necessidade de se comunicar com ele.

Os três primeiros anos de vida são marcos da apropriação dos conteúdos da língua materna que se torna uma das principais metas do ato educativo. O papel potencialmente mediador do educador implica, assim, o estabelecimento de uma relação direta de comunicação com a criança, demonstrando ações com objetos e atitudes, orientando, questionando, propondo, estabelecendo contato com ela, em situações pedagógicas orientadas ao desenvolvimento integral da linguagem.

As realizações potencialmente humanizadoras nas instituições de Educação Infantil são, portanto, resultado de atividades pedagógicas intencionalmente voltadas para o desenvolvimento integral das crianças, o que envolve a aprendizagem da linguagem oral e seu domínio paulatino. As crianças pequenas merecem ter acesso a diferentes formas de apropriação e de exploração do conhecimento por meio de vivências lúdicas, artísticas, comunicativas e expressivas, ao considerarmos que a comunicação oral é uma das capacidades psíquicas especificamente humanas envolvida nos momentos de criação e de criatividade.

\section{Referências}

Brasil. Lei n. 9.394, de 20 de dezembro de 1996. (1996, 23 de dezembro). Estabelece as Diretrizes e Bases da Educação Nacional. Diário Oficial da União, seção 1.

Brasil. Constituição da República Federativa do Brasil. (1988, 5 de outubro). Recuperado em 10 de abril de 2012,

http://www.planalto.gov.br/ccivil_03/Constituicao/Co nst/

Brasil. Parecer n. 20, de 11 de novembro de 2009. (2009, 11 de novembro). Revisão das

Diretrizes Curriculares Nacionais para a Educação Infantil. Conselho Nacional de Educação/Câmara de Educação Básica. Ministério da Educação. Brasília, DF CNE/CEB/MEC. Recuperado em 10 de abril de 2012, de http://portal.mec.gov.br/

Fonseca-Janes, C. R. X. e Lima, E. A. de.(2013). O processo de formação de conceitos na perspectiva Vigotskiana. Revista da FAEEBA: Educação $e$ Contemporaneidade. Universidade Estadual da Bahia, Departamento de Educação, Salvador, BA. v. 22, n. 39, pp. 229-237, jan./jun.

Liamina, G. M. (et. al.) (1982). La educación de los niños en la edad temprana. Havana: Pueblo y Educación.

Lísina, M. (1987). A gênese das formas de comunicação nas crianças. In: DAVIDOV, V.; SHUARE. M. (Org.). La Psicologia Evolutiva y Pedagógica en la URSS (Antologia).(pp. 274-298).

Moscou: Editoral Progresso, 1987.

Popova, M. I. El Lenguaje de los niños de edad temprana. In: SOJIN, F. A. (et al.) El desarollo del lenguaje en los niños de edad preescolar. Havana: Pueblo y Educación, 1985. p. 19-51.

Vygotski, L. S. (1995). Obras Escojidas. Vol. III, Madrid: Visor.

(1998a). Pensamento e linguagem. Tradução Jeferson Luiz Camargo. 2.ed. São Paulo: Martins Fontes, (Série Psicologia e Pedagogia)

(1998b). O desenvolvimento psicológico na infância. Tradução Cláudia Berliner. São Paulo: Martins Fontes, (Série Psicologia e Pedagogia)

. (2004). Teoria e método em psicologia. Tradução

Cláudia Berliner. 3.ed. São Paulo: Martins Fontes. (Série Psicologia e Pedagogia). 